\title{
A Case Study of the Revision Process of a Reluctant ESL Student Writer
}

\section{Celine Sze}

This case study investigated the revision process of a reluctant ESL student writer. It focused on revisions made at the in-process stage and at the betweendraft stage of the writing process in which the student revised in response to written feedback. Two writing assignments were given, and the topics varied in their degree of familiarity to the participant. Some findings corroborated those of earlier studies: the participant made more surface-level revisions than those related to structure and content; he made more revisions and high-level revisions in response to written feedback than when working on his own. Although familiarity with the topic seemed to have no effect on the revision patterns of the student, the classroom teacher's focus on form in responding to and evaluating his writing was seen to affect his attitude toward revision and use of revision strategies.

Cette étude de cas porte sur le processus de révision qu'élaborait un étudiant en ALS qui abordait la rédaction à contrecaur. La recherche s'est penchée sur les révisions effectuées lors des étapes de la rédaction et de la révision alors que l'étudiant retravaillait son texte en réaction à des commentaires écrits. L'étudiant devait écrire deux textes; il connaissait mieux un des thèmes que l'autre. Quelques-uns des résultats corroborent ceux des études antérieures. D'une part, les révisions de l'étudiant consistaient davantage en des changements cosmétiques que des modifications liées à la structure ou au contenu; d'autre part, il a fait plus de révisions globalement et plus de révisions en profondeur face à la rétroaction écrite qu'il a fait quand il travaillait seul. Alors que sa connaissance du thème imposé ne semblait pas influencer le processus de révision adopté par l'étudiant, la rétroaction de l'enseignant quant à la forme de ses rédactions modifiait son attitude face à la révision et son emploi de stratégies de révision.

\section{Introduction}

Over the past 20 years, an important part of the writing research studied the revision process of student writers. In the context of multi-draft process writing, revision is an integral part of the process. Taylor (1981) described it as a "creative discovery procedure." Soven (1999) defined it as the act of "reconsidering the larger elements of an essay, its content, development and organization" (p. 16). It is distinguished from editing, which refers to correction of what has been written, where the focus is on sentence correctness, 
spelling, usage, and punctuation. Bridwell (1980) describes the composing process as both linear and recursive. In the course of writing, the writer conceives of an idea and proceeds linearly, unfolding and elaborating the concept, but at certain moments he or she stops to reread or scan the product to "verify what is on the page or perceive some dissonance" (p. 220). Perception of the dissonance would lead to a decision to change, to stop, or to simply ignore it and go on. The underlying assumption is that the process is a loop and goes on until all dissonance is resolved or until the point when the writer sees no need for further revision

This article reports a descriptive case study of the revision process of an ESL student whose writing ability needs further development. Much L2 research has sought to compare the skilled and unskilled writer. Results suggest that their respective approaches to revision account for much of the difference in their written products (Porte, 1997). This study explores some of the causes of several ineffective revisions of a reluctant and inexperienced ESL student writer.

\section{Theoretical Background}

A substantial body of research has been conducted to study the revision process in both first- and second-language writing. In studies of the types of revisions made by L2 student writers, there is overwhelming consensus that they tend to focus on sentence-level concerns just as their L1 counterparts do. The L2 student writers look on revision as an activity that affects only the surface aspects of the text; they revise by looking more at surface than content features (Porte, 1997). Gaskill (1987, cited in Ferris, 1997) reported that ESL student writers regard revision as a proofreading exercise that focuses on the word level.

In studying student writers' response to feedback, some researchers reported that ESL students attend to and value teacher comments on their errors in writing (Cohen, 1987) and that they make many form-based revisions in their writing (Tagong, 1992; Lai, 1986, cited in Ferris, 1997). Their preference has been endorsed by recent reviews and surveys that confirm the merits of form-based feedback on L2 writing (Fathman \& Whalley, 1990; Ferris, 1995; Hedgcock \& Lefkowitz, 1994). However, it has also been shown that these student writers are interested in teacher feedback on content as well as sentence-level comments and corrections, although they still prefer extensive comments on grammar (Ferris, 1995).

Among ESL student writers, as among native English learners, the composing ability varies greatly. Sommers (1980) suggests that the most important revisions for competent writers involve larger units of discourse. Competent writers also take more responsibility for their writing and revision. On the other hand, incompetent L2 student writers seldom make self-initiated revisions, but just respond directly to the teacher's comments, 
making local revisions that hardly improve the quality of the paper (Conrad \& Goldstein, 1999). The inexperienced student writers are seen to revise from a narrow outlook, focusing their revision on surface features rather than the issues of content and organization, normally making changes limited to addressing the surface and grammatical structure of composing.

Research into revision by L1 students shows that teacher feedback has an effect on the revisions made by student writers. Studies reveal that among L1 senior high school students, teacher evaluation between drafts results in more extensive revision than when students are revising on their own (Beach, 1979; Yagelski, 1995). In studying the level of revisions made at different stages of process writing, Bridwell (1980) found that student writers made more surface and word-level revisions when writing the second drafts than when writing the first drafts. However, Yagelski's (1995) findings contradicted this; the percentage of surface changes made by his participants dropped from $38.2 \%$ of total revisions on the first draft to $24.1 \%$ of total revisions on the second draft after receiving response from the teacher. $\mathrm{He}$ attributed this divergence to the influence of the nature of writing instruction the student writers in his study received, suggesting that specific features of some instructional contexts might have led students to focus on lower-level concerns.

Hence some researchers examined the classroom context for explanations for ineffective revision or absence of revision. They explored the connections between particular features of the instructional approach and teaching strategies and the revision patterns of the students in terms of frequency and types of revision (Bridwell, 1980; van Gelderen, 1997). The nature of the teachers' strategies and criteria for evaluation of students' writing may account for students' revision practices. It is believed that these strategies and criteria serve to reinforce traditional views of what constitutes good writing and revision, resulting in students' paying undue attention to lower-level concerns in revision. Therefore, as pointed out by Yagelski (1995), the process writing orientation of a composition classroom with its prewriting activities, multiple drafts, and peer editing can be offset by the teacher's grading practices that focus on linguistic accuracy and form rather than content and organization.

\section{The Study}

\section{Research questions}

The study addressed three research questions:

1. What types of revisions did the reluctant ESL student writer make in the process of writing a composition?

2. What were the frequencies of the different types of revisions made in the in-process and between-draft stages of the composing process? 
3. Did classroom practices in evaluation and teacher commentary have an effect on the revision strategies of this ESL student writer?

\section{The Participant}

The participant is an ESL student writer enrolled in grade 11 in a suburban high school. Chung Yin (a pseudonym) immigrated to Vancouver from Hong Kong four years ago. After spending a semester in an ESL class, he was transferred to mainstream English in grade 8. Never having had much success in learning English as a second language in Hong Kong, he is struggling in English language classes as well as content subject courses because of his low proficiency in the language. He has not made satisfactory progress in any of his school subjects, nor has he established any close relationships with his teachers or peers in the school. He seems to suffer from low self-esteem, an impression derived from his lamenting his inability to measure up to the standards of his peers whenever he gets poor grades for his school work. Awareness of his plight has not, however, prompted him to spend more effort or time in his studies. Accepting things as they are, he gives one the impression that he is not ready to make any investment for academic advancement, for lack of either a foreseeable likely return or an effective way for going about it.

With regard to writing in English, Chung Yin does not seem to have made much progress despite his being in the local school system for four years. He is reluctant to do writing assignments for either English or social studies. He always tries to do the least possible, just aiming to meet the minimum requirements of the teacher. He avoids writing prose in English at all costs, be it academic reports or journals, often trading off writing with his peers or teachers with other kinds of work such as graphics or writing a poem. When pressed to write, Chung Yin produces short, single-paragraph essays that are generally weak in organization, content, and accuracy. His school-sponsored writing usually consists of one-off pieces of work done in class or at home. They are handed in and later returned to the student with some brief comments and a grade given at the end of the composition. The teacher comments tend to focus on grammatical accuracy and style. Seldom has Chung Yin been required to revise his work or respond to the feedback given. The grades he gets for his written assignments are always low, and feedback from his teachers is seldom complimentary. His reluctance to do written composition goes far to explain why he remains an unskilled writer despite his grade level. All in all, he lacks confidence, skill, and interest in writing in English. However, he demonstrates a creative mind and critical thinking skills as observed in his oral interactions with others in his native language. 


\section{Method}

\section{Theoretical Input}

The participant was briefed on what constituted good writing. He was brought to understand that a piece of writing should be rated not only for accuracy and style, but also for structure and content. Ideas and ways of presenting them were just as important as accuracy in grammar and mechanics. He was also introduced to the concept of process writing. It was pointed out to him that revision was an integral part of the writing process, and a piece of good writing was often the culmination of one or more revisions. The revisions could span over different levels, ranging from lowlevel surface matters to broader concerns like organization and content. The main goal was not the product, but rather the process, and revision practice was aimed at helping him to write and revise his written composition more effectively in future writing assignments.

\section{Data collection}

Two types of data were collected for analysis.

Writing assignments. The participant was given two writing assignments for the purpose of the study. Both written assignments were of an expository type; the first was on a familiar topic and the second on an unfamiliar topic (see Appendix A for the instructions for the individual assignments). This design was adopted with a view to comparing the revision process across two topics for which the participant had different content knowledge and experience. The participant wrote all drafts of each paper at home while the researcher observed. To prepare the participant for the written assignments, there was a prewriting activity at the beginning of each writing session. This consisted of explaining the instructions for the assignment and a reading task in which the participant read a newspaper article related to the writing topic for the purpose of input. This was followed by a brief discussion of the issues concerned.

For each writing assignment, Chung Yin had to produce two drafts. The first was written in blue pen; then, after he finished writing it, he was asked to revise it on his own with a red pen. This served to differentiate the revisions made in the in-process stage when he produced the writing from those made in the between-draft stage, namely, when he revised the first draft after completion. Then the researcher read the first draft and gave written feedback. The feedback was phrased in positive terms and consisted of:

1. notes on style, organization, and content and symbols for corrections on grammatical accuracy written in the margin;

2. general comments on organization and content, suggestions for general directions to improve the essay, and response to ideas written at the end of the draft. 
The assignment was marked and returned to the participant with the commentary in the next meeting. Then he wrote a second (final) draft of the paper in response to the written comments. The researcher was available for consultation and explanation of the comments. The same procedure was repeated in writing the second draft-the student first wrote in blue and made changes to the second draft with a red pen after he finished writing it. The second draft of the assignment was marked and returned to the participant with written feedback on organization, content, and general performance.

Interviews. A tape-recorded interview was conducted with the participant at the end of the first draft and the second draft of each assignment to collect data on his revision strategies and his reasons for deciding what to revise, when to revise, and how to revise. The participant was interviewed again after completing the two written assignments to collect data on the classroom practices and teaching strategies he experienced in his English classes in order to examine how they influenced his revision strategies. All interviews were conducted in Cantonese, the home language of the participant.

\section{Data Analysis}

An analysis was conducted of the revisions made by the student writer in each of four stages of composing the essay in terms of types of revisions and stages of writing the paper. Frequency counts and percentages were used for analyzing the data. A coding scheme was used to code each of the revisions made. It is a scheme adapted by Yagelski (1995) from one developed by Bridwell (1980) and Faigley and Witte (1981). Some slight modification has been made to the scheme to fit the purpose of the present study (see Appendix B for the coding scheme for the analysis).

The recordings of the various interviews were transcribed and translated into English. Notes were made of the participant's responses to questions on the choice and use of revision strategies as well as his experiences of classroom practices related to evaluation and teacher feedback.

\section{Results and Discussion}

\section{Levels and Frequencies of Total Revisions}

For the purpose of analysis, revisions made in the written assignments were coded according to the coding scheme shown in Appendix B. They were classified into different levels to signify their nature. As outlined in Table 1, the first three levels are those regarded as lower-level changes, namely, surface changes or mechanics, lexical changes, and phrasing changes. The fourth and the fifth levels are related to changes in organization and content.

The total number of revisions coded in the two drafts of the written assignments was computed with regard to the level at which a revision was made. As seen in Table 1, the sum of the first three levels in frequency 
exceeded by far that of the fourth and the fifth levels. For the first written assignment, the topic of which was familiar to the participant, the surfacelevel changes (mechanics, lexical, and phrasal changes) made up $76.7 \%$ of the 30 revisions. The percentage was similar for the second assignment in which the participant wrote an essay on an unfamiliar topic. In this assignment, $71.1 \%$ of the revisions belonged to the first three levels. This indicates that in general the participant paid more attention to revisions related to mechanics, word, and phrase-level changes. This finding corroborates those of previous studies that suggest student writers made more lower-level changes than content and organization changes in revising (Porte, 1997; Gaskill, 1987, cited in Ferris, 1997).

\section{Revision Patterns in the Different Stages of Writing the Composition}

The data were further analyzed to study the revision patterns of the participant in the composing process. Four stages were identified:

1. the in-process first draft stage in which the participant revised as he reread the paper while writing;

2. the between-draft stage in which he revised the completed first draft on his own;

3. the in-process second draft stage in which he made revisions in response to written feedback on the first draft;

4. the post-second draft stage in which he revised the completed final draft on his own.

Table 2 shows the frequencies and percentages of all levels of revisions made in each of the four stages. It can be seen that for Topic 1 , the greatest number of changes at all levels occurred during Stage $C$, that is, when the participant was revising the first draft in response to written commentary. For Topic 2 the greatest number of revisions was found in Stage D, rather

Table 1

Frequencies and Percentages of Total Revisions at Levels

\begin{tabular}{lcccc}
\hline \multirow{2}{*}{ Level } & \multicolumn{2}{c}{ Topic 1 } & \multicolumn{2}{c}{ Topic 2 } \\
& Frequency & Percentage & Frequency & Percentage \\
\hline 1. Surface & 5 & 16.7 & 16 & 30.8 \\
2. Lexical & 8 & 26.7 & 17 & 32.6 \\
3. Phrasal & 10 & 33.3 & 4 & 7.7 \\
4. Structural & 6 & 20.0 & 4 & 7.7 \\
5. Content & 1 & 3.3 & 11 & 21.2 \\
& & & 52 & 100.0 \\
\hline
\end{tabular}


Table 2

Frequencies and Percentages of Total Revisions at Stages

\begin{tabular}{lrccc}
\hline \multirow{2}{*}{ Stage } & \multicolumn{2}{c}{ Topic 1 } & \multicolumn{2}{c}{ Topic 2 } \\
& Frequency & Percentage & Frequency & Percentage \\
\hline 1. In-process first draft & 5 & 16.7 & 11 & 21.2 \\
2. Between-draft & 7 & 23.3 & 7 & 13.5 \\
3. In-process second draft & 18 & 60.0 & 15 & 28.8 \\
4. Post-second draft & 0 & 0.0 & 19 & 36.5 \\
\hline & 30 & 100.0 & 52 & 100.0 \\
\hline
\end{tabular}

than Stage $\mathrm{C}$ as in Topic 1. Thus in terms of frequencies for revisions at all levels, the student writer made fewer revisions in the in-process first draft and between-draft stages than in the other two stages: he revised less extensively when doing it on his own than when responding to and guided by written commentary. It can be concluded that written feedback resulted in more revising than the participant revising by himself. This finding paralleled that reported in other related studies (Beach, 1979; Bridwell, 1980; Yagelski, 1995).

\section{Levels of Revision at Different Stages of Writing}

The levels of revisions made at different stages of revision are shown in Tables 3 and 4 . It can be seen that the student writer made more structural and content changes (levels 4 and 5) to his second draft than he did to his first draft for both assignments. These high-level revisions increased from $0 \%$ to $23.3 \%$ of the total revisions for the first assignment and from $3.5 \%$ to $25 \%$ for the second. This is related to a finding reported by Yagelski (1995) re-

Table 3

Percentage of Revisions by Type per Draft (Topic 1)

\begin{tabular}{lcccccc}
\hline & surface & lexical & phrasal & structural & content & \\
& 1 & 2 & 3 & 4 & 5 & Total \\
\hline 1. In-process 1st draft & 0 & 10.0 & 6.7 & 0 & 0 & 16.7 \\
2. Between draft & 3.3 & 13.3 & 6.7 & 0 & 0 & 23.3 \\
3. In-process 2nd draft & 13.3 & 3.3 & 20.0 & 20.0 & 3.3 & 60.0 \\
4. Post second draft & 0 & 0 & 0 & 0 & 0 & 0 \\
\hline
\end{tabular}


Table 4

Percentage of Revisions by Type per Draft (Topic 2)

\begin{tabular}{lcccccc}
\hline & $\begin{array}{c}\text { surface } \\
1\end{array}$ & $\begin{array}{c}\text { lexical } \\
2\end{array}$ & $\begin{array}{c}\text { phrasal } \\
3\end{array}$ & $\begin{array}{c}\text { structural } \\
4\end{array}$ & $\begin{array}{c}\text { content } \\
5\end{array}$ & Total \\
\hline 1. In-process 1st draft & 9.6 & 8.2 & 0 & 3.5 & 0 & 21.3 \\
2. Between draft & 3.8 & 7.7 & 1.9 & 0 & 0 & 13.4 \\
3. In-process 2nd draft & 1.9 & 0 & 1.9 & 3.8 & 21.2 & 28.8 \\
4. Post second draft & 15.4 & 17.3 & 3.8 & 0 & 0 & 36.5 \\
\hline
\end{tabular}

100.0

searching first language senior high school student writers; the participants revised differently in response to the teacher's feedback than they did when working on their own.

\section{Familiarity of Topic}

Evidence from research findings is conflicted with regard to the degree of success shown by student writers when writing on familiar and unfamiliar topics. Studies suggest that regardless of the age and level of the student writer, whether writing a first draft or revising, the writing product is of better quality if the writer has greater knowledge of the content (Scardamelia \& Bereiter, 1987; Ackerman, 1990). An earlier study by Scardamalia, Bereiter, and Woodruff (1980), however, reported that compositions written by grades 4 and 6 students showed no differences between those on familiar and others on unfamiliar topics, as measured in six different dimensions. The results in this study corroborated the above findings; the second assignment on the unfamiliar topic was written in greater depth, richer in content, and with better organization than the first. This might be explained by one or more of the following reasons.

1. Result of extra practice: the student writer reported in the interview after the second written assignment that the extra practice and tutorials helped him to focus his attention on cues given in feedback, and hence he was able to pick them up more easily than before. Excerpts from the interviews are selected to illustrate his views and practices. The transcripts have been translated into English from Cantonese. The participant reported in the interview conducted after he finished the second draft of the second assignment: "Because I had to revise the essay, I read the comments... They pointed to me things that I didn't pay attention to before." (November 25, 2000) 
2. Motivation and encouragement: in the interview after the second draft of the first assignment, the participant showed great pleasure and satisfaction with the comments he received on the improvements he made to the composition: "I knew I could do it.... If I spend more time and try hard I can revise an essay and improve it.... I got wonderful ideas." (November 25, 2000)

3. Provision of input: the newspaper article supplied content knowledge that the participant could make use of in his second assignment, although the topic was unfamiliar to him. In the interview after the first draft of the second assignment he reported: There were many points in the newspaper article. I used some of them and put them together with my ideas. (November 18, 2000)

\section{Revision Strategies}

Findings of the present study corroborated findings from some earlier studies. Emig (1971) reported that students did not revise school-sponsored assignments unless required to do so. Zamel (1985) also points out that although teachers suggest revision, they do not provide for or request further revision. Pianko (1979) found that her student writers made no "major reformulations" (p. 10). In one of the interviews conducted at the completion of each draft, the participant said that he rarely read his writing for revision, for both timed writing in class and take-home assignments.

I'm seldom asked to revise by my teachers in school. I don't feel the need to revise and improve my work. When I finish writing an essay, I just put it away or hand it in. (November 11, 2000)

However, the participant demonstrated awareness of certain revision skills. He even knew how to apply some grammatical and rhetorical constructions to make stylistic revisions to his writing.

I don't want to repeat the word too many times. I substituted it with a similar word or a pronoun, such as one. (November 11, 2000)

Putting the subject in front of the whole bunch of adjectives [a relative clause] would be better. In doing so you put the subject in focus.

(November 11, 2000)

He was also able to use some of the punctuation conventions he has learned:

I reread the previous sentence and this one. They seem related, so I used a semicolon. For sentence breaking I read the sentences to find out how they are related. (November 11, 2000)

The awareness and knowledge of revision skills, however, did not help him to improve his writing much, simply because he did not choose to 
revise. In referring to his school written assignments, he showed the following conception of the process of writing:

The first draft is just a rough copy, isn't it? The second draft, well, that is supposed to be a fair copy of the essay. So I just copied it once. (November 11, 2000)

Interestingly, when Chung Yin talked about revising his drafts, he focused on issues of content and organization rather than grammar.

I find making revisions on content and organization easier than grammar; they are more related to concepts [rather than syntactic and semantic choices]. I have little knowledge of grammar. I don't know how to correct the grammar mistakes by myself. (November 18, 2000)

In responding to feedback on grammar and mechanics, Chung Yin felt quite at a loss. He found that checking the dictionary did not help at all. Instead he adopted the following strategy:

I understand these symbols and the comments about adding details and paragraphing. But I'm going to rewrite the essay, so they're not relevant any more. (November 18, 2000)

As for his approach to revision in writing, Chung Yin professed the following view:

Revising is not really that difficult. It all depends on how much time you have and how much you want to improve the quality of your writing. (November 25, 2000)

It was noted that one of the revision strategies adopted by the participant was rewriting. Sometimes he ignored most of the feedback related to grammar and chose to rewrite chunks of text instead of revising them. He placed greater emphasis on expression of ideas than on formal accuracy. This approach did not help to improve his writing or revision processes, however. As pointed out by Hyland (1998), it "bypasses an important step in the revision process: diagnosing the nature of the problems in the original text" (p. 277).

\section{Relations Between the Learning Context and Student Writer's Revision}

Studies on the role of the classroom context in the revision strategies of student writers (Porte, 1997; Yagelski, 1995) drew connections between the particular features of the teacher's approach to writing and revision instruction and the frequency and types of revisions students made to their writing. The learning context the participant experienced did not seem to encourage him to revise his compositions. It was not clear what the general evaluation 
approach was for the whole class, but in Chung Yin's case, the feedback he received from his teacher tended to focus more on form than on content. The feedback procedure adopted by the teacher was one-to-one conferencing. The commentary given was "always the same thing-I'm not writing idiomatic English, and the grammar is all wrong," Chung Yin reported. After conferencing, the paper was returned to the student with a grade at the end and grammatical errors circled. Some comments in the margin and at the end were also given. But again, the comments mostly dwelt on accuracy. This is not surprising because research findings show that teachers take a more collegial and less directive stance in giving feedback to more skilled learners, but focus more on surface-level errors in dealing with the unskilled student writers (Freedman \& Sperling, 1985). The teachers' perceptions of the needs and interests of the second-language learner might also result in this focus.

The situation constructed from Chung Yin's interview did not seem to promote an active strategy in text revision. He was not capable of revising grammar mistakes on his own. He might have fared better if his teacher had focused more on revision in content and organization. Moreover, he had seldom been asked to revise or submit a second draft of an essay, nor had he been given any instruction in revision strategies.

\section{Conclusions}

In conclusion, the present findings can be summarized as follows.

1. The participant made more surface-level revisions than those related to structure and content in his writing. This coincided with earlier findings about the revision of L2 student writers (Tagong, 1992; Lai, 1986, cited in Ferris, 1997).

2. He made more revisions in writing the second draft of the paper that contained teacher comments than in the first draft, which did not. This finding is similar to those of earlier studies of first-language student writers (Beach, 1979; Bridwell, 1980; Yagelski, 1995).

3. Feedback from the teacher affected not only the total number of revisions, but also the types of revisions made. Yagelski (1995) saw a drop in the number of surface revisions when his participants wrote their second drafts in response to teachers' comments. In the present study, more revisions related to structure and content were made in Stage C (in-process second draft) than in Stage A (the in-process first draft). The observation can be seen as a function of written commentary: the written feedback encouraged more high-level revision by the participant.

4. Familiarity with the topic seems to have no effect on the revision patterns of this ESL student writer, contrary to findings of earlier studies. The second assignment had more revisions and was of better 
quality. This can also be considered an interaction of practice, improved motivation derived from positive feedback, and the provision of input.

5. The revision strategies of the participant were identified as follows: (a) did not revise at all unless required to do so, similar to the native speakers of English reported by Emig (1971); (b) did not perceive the need to revise; (c) paid little attention to feedback on grammar because he was not capable of dealing with the errors by himself; (d) did not employ available resources to revise his writing; (e) saw the first draft as a rough copy and the second draft as merely a fair copy; (f) did not focus on specific comments on grammar, organization, and content given in the margin, thinking they would be irrelevant if he were to rewrite the composition. His approach to revision and revision strategies appeared to affect his revision process and the quality of his writing.

6. The classroom context might have a role to play in the revision strategies of this ESL student writer. The teacher's focus on form in his feedback might have made the participant feel incompetent about his own writing. The participant was capable of making extensive revisions in content and organization as reflected in the present study. However, he was seldom required by the teacher to revise or produce a second $\mathrm{draft}$. The lack of revision instruction did not help to improve the situation either.

7. The instructional context provided by the researcher seemed to have a positive effect on the participant's approach to revision and use of revision strategies. With constructive and positive written commentary focusing on various aspects of writing rather than just on grammatical accuracy, the participant was encouraged to examine his work more critically and revise his writing to improve its quality.

The above findings have some pedagogical implications. In working with ESL students, teachers may need to review some traditional concepts of what constitutes good writing and on what aspects of writing revision should focus to be effective. Recent research reveals that second-language learners pay attention to content as well as form and grammar (Ferris, 1995). Moreover, Leki (1990) pointed out that ESL students have different needs for feedback and different strategies for processing teachers' responses. Teachers may wish to communicate with their students to learn their perceived and real needs. An excessive concern for correctness may stifle the generating of ideas, a composing skill that all learners should acquire.

This study examined the revision process of a specific underachieving ESL student writer who is reluctant to write and to revise. The findings and implications are, therefore, suggestive rather than definitive. But the case study serves to reveal, at least to a limited extent, the interaction of teacher feedback, students' revision strategies, and classroom context in the writing 
process of one novice ESL student writer. Much more extensive research is needed to discover effective ways to help ESL student writers to revise, balancing acquisition of linguistic accuracy with compatible development in content and organization. An interesting direction for future research would be to investigate the appropriateness of approaches in teaching ESL writing currently adopted and endorsed by the school system. It is felt that the instruction that the participant has been receiving in his school is somewhat behind current research in the field. There is a need to examine whether the issues faced by the participant are widespread in the school system in terms of focus, priorities, and processes of providing instruction and feedback in teaching ESL writing. Such inquiry would be of great interest and concern to the community of teachers who either teach ESL writing programs or have ESL students in their writing composition classes.

\section{The Author}

Celine Sze has taught for 14 years in Hong Kong. Her research interests include written composition, learner autonomy, and materials design.

\section{References}

Ackerman, J.M. (1990). Reading, writing and knowing: The role of disciplinary knowledge in comprehension and composing (Technical Report No. 40). Berkeley, CA and Pittsburgh, PA: Center for the Study of Writing.

Beach, R. (1979). The effects of between-draft teacher evaluation versus self evaluation on high school students' revising of rough drafts. Research in the Teaching of English, 13, 111-119.

Bridwell, L.S. (1980). Revising strategies in twelfth grade students' transactional writing. Research in the Teaching of English, 14, 197-222.

Cohen, A. (1987). Student processing of feedback on their compositions. In A.L. Wenden \& J. Rubin (Eds.), Learner strategies in language learning (pp. 57-69). Englewood Cliffs, NJ: Prentice-Hall.

Conrad, S., \& Goldstein, L.M. (1999). ESL student revisions after teacher-written comments: Text, contexts and individuals. Journal of Second Language Writing, 8, 147-177.

Emig, J. (1971). The composing process of twelfth graders. Research Report No. 13. Urbana, IL: NCTE ED 058205.

Faigley, L., \& Witte, S. (1981). Analyzing revision. College Composition and Communication, 32, 400-414.

Fathman, A., \& Whalley, E. (1990). Teacher response to student writing: Focus on form versus content. In B. Kroll (Ed.), Second language writing: Research insights for the classroom (pp. 178-190). New York: Cambridge University Press.

Ferris, D.R. (1995). Student reactions to teacher response in multiple-draft composition classrooms. TESOL Quarterly, 29, 33-53.

Ferris, D.R. (1997). The influence of teacher commentary on student revisions. TESOL Quarterly, 31, 315-339.

Freedman, S., \& Sperling, M. (1985). Written language acquisition: The role of response and the writing conference. In S. Freedman (Ed.), Acquisition of the written language: Response and revision (pp. 106-130). Norwood, NJ: Ablex.

Hedgcock, J., \& Lefkowitz, N. (1994). Feedback on feedback: Assessing learner receptivity to teacher response in L2 composing. Journal of Second Language Writing 3, 141-163.

Hyland, F. (1998). The impact of teacher written feedback on individual writers. Journal of Second Language Writing, 7, 255-286. 
Leki, I. (1990). Coaching from the margins: Issues in written response. In B. Kroll (Ed.), Second language writing: Research insights for the classroom (pp. 57-68). New York: Cambridge University Press,

Pianko, S.H. (1979). A description of the composing acts of college freshman writers. Research in the Teaching of English, 13, 5-22.

Porte, G.K. (1997). The etiology of poor second language writing: The influence of perceived teacher preferences on second language revision strategies. Journal of Second Language Learning, 6, 61-78.

Scardamalia, M., \& Bereiter, C. (1987). Knowledge telling and knowledge transforming in written composition. In S. Rosenberg (Ed.), Advances in applied psycho-linguistics (pp. 142-175). Cambridge, UK: Cambridge University Press.

Scardamalia, M., Bereiter, C., \& Woodruff, E. (1980). The effects of content knowledge in writing. Paper presented at the annual meeting of AERA, Boston.

Sommers, N. (1980). Revision strategies of student writers and experienced adult writers. College Composition and Communications, 31, 378-388.

Soven, M.I. (1999). Teaching writing in middle and secondary schools: Theory, research and practice. Toronto, ON: Allyn and Bacon.

Tagong, R. (1992). Revising strategies of Thai students: Text-level changes in essays written in Thai and in English. Dissertation Abstracts International, 52, 2849A.

Taylor, B.P. (1981). Content and written form: A two-way street. TESOL Quarterly, 15, 5-13.

van Gelderen, A. (1997). Elementary students' skills in revising: Integrating quantitative and qualitative analysis. Written Communication, 14, 360-397.

Yagelski, R.P. (1995). The role of classroom context in the revision strategies of student writers. Research in the Teaching of English, 29, 216-238.

Zamel, V. (1985). Responding to student writing. TESOL Quarterly, 19, 79-101.

\section{Appendix A: Instructions for the Written Compositions}

\section{Topic 1}

Write an essay to introduce Hong Kong to a friend in Vancouver. Describe the tourist attractions in the territory and explain why he or she should visit the place. Use (a) your knowledge and experience of living in Hong Kong to support your arguments, and (b) the information from the newspaper article "Hong Kong on a Platter."

\section{Topic 2}

Read the article "Alouette Lake turns Bountiful: What was previously a sterile body of water is being transformed into a successful fishery." Write a letter to a scientist in the Agriculture and Fishery Department in Hong Kong and describe the possible ways of reviving fish life and vegetation in a coastal fishing ground that has turned sterile because of heavy pollution.

\section{Appendix B: Coding Scheme for Revisions}

1. Surface changes (Mechanics)
a. punctuation
b. spelling
c. capitalization 

d. pluralization
e. word form corrections other than pluralizations (e.g., subject-verb agreement, verb tense changes)
f. substitution

2. Lexical changes
a. stylistic substitution (e.g., several for a few)
b. addition or deletion of a single word

3. Phrasing changes
a. syntactic-meaning-preserving rewording, including adding or deleting words (e.g., to avoid a awkward construction)
b. structural-meaning-preserving sentences restructuring (e.g., When we went outside for Having gone outside)

4. Structural changes
a. organization (within paragraphs; within essay)
b. paragraphing (moving whole paragraphs; creating new paragraphs from existing ones)

5. Content changes
a. addition of new material (e.g., new subject matter or ideas-as distinct from simply adding new words to tighten a phrase or sentence to develop the subject or clarify points)
b. deleting material (e.g., deleting subject matter or ideas-as distinct from deleting words to make a sentence or phrase tighter)
c. altering an idea, argument, etc. (e.g., changing from pro to con on an issue; shifting focus form description to narration)

